\title{
Splenic Abscess: An Unusual Presentation of COVID-19?
}

\author{
Labib S. Al-Ozaibi ${ }^{a}$ Mohammed O. Alshaikh ${ }^{\text {a }}$ Maahroo Makhdoom ${ }^{\text {a }}$ \\ Osama M. Alzoabi ${ }^{a}$ Hajar A. Busharar ${ }^{\mathrm{a}}$ Tasnim R. Keloth $^{\mathrm{b}}$ \\ ${ }^{a}$ General Surgery Department, Rashid Hospital, Dubai Health Authority, Dubai, UAE; b Histopathology Department, \\ Dubai Hospital, Dubai Health Authority, Dubai, UAE
}

\section{Keywords}

Splenic abscess · COVID-19 · Novel coronavirus disease 2019

\begin{abstract}
Most patients with coronavirus disease 2019 (COVID-19) present with respiratory symptoms that range from mild symptoms to severe illness leading to mortality. Some might be asymptomatic and others may present with unusual presentations. A 55-year-old male with a past history of ischemic stroke, ischemic heart disease, and type 2 diabetes mellitus presented with right-sided weakness and a history of abdominal pain, diarrhea, and fever. He tested positive for COVID-19. Computed tomography (CT) abdomen showed the presence of splenic abscess and small intraperitoneal gas indicating pneumoperitoneum. Laparotomy revealed ruptured splenic abscess and splenectomy was done. The patient continued to show features of severe sepsis with multiorgan failure and died on postoperative day 16. COVID-19 mainly affects the respiratory system but extrapulmonary affection has been reported. Direct invasion and damage to the organs by the virus could be the reason behind the development of the extrapulmonary manifestations.
\end{abstract}

(C) 2020 The Author(s)

Published by S. Karger AG, Basel

\section{Introduction}

Since its emergence in December 2019, asymptomatic and atypical presentations of coronavirus disease 2019 (COVID-19) remain a challenge for healthcare workers. This raises a concern that this virus might have the capability of attacking not only the respiratory system but also almost every single organ system. In addition, it may not present with respiratory symptoms. Patients with the virus have presented with features of acute liver injury, gastrointestinal symptoms, endocrine problems, neurological damage, and cardiovascular disease. It is still unclear whether the virus had a direct causal effect or the patients' underlying disease played a factor.

We present a case of acute abdomen due to ruptured splenic abscess in a COVID-19 patient with no features of respiratory involvement on presentation.

\section{Case Presentation}

A 55-year-old male patient with type 2 diabetes mellitus on insulin, previous history of ischemic stroke, ischemic heart disease, and chronic kidney disease presented to the emergency department with right-sided weakness, aphasia, fever, and history of abdominal pain and diarrhea 1 day prior to admission.

He was admitted to our hospital with a working diagnosis of left middle cerebral artery stroke and sepsis. Upon examination,

\begin{tabular}{ll}
\hline karger@karger.com & $\begin{array}{l}\text { (c) 2020 The Author(s) } \\
\text { Published by S. Karger AG, Basel Openger } \\
\text { www.karger.com/dmj }\end{array}$ \\
Karger & This article is licensed under the Creative Commons Attribution- \\
& NonCommercial-NoDerivatives 4.0 International License (CC BY- \\
NC-ND) (http://www.karger.com/Services/OpenAccessLicense). \\
Usage and distribution for commercial purposes as well as any dis- \\
tribution of modified material requires written permission.
\end{tabular}

Labib S. Al-Ozaibi

General Surgery Department

Rashid Hospital, Dubai Health Authority

Oud Metha Street, PO Box 4545, Dubai (UAE)

lsalozaibi@gmail.com 


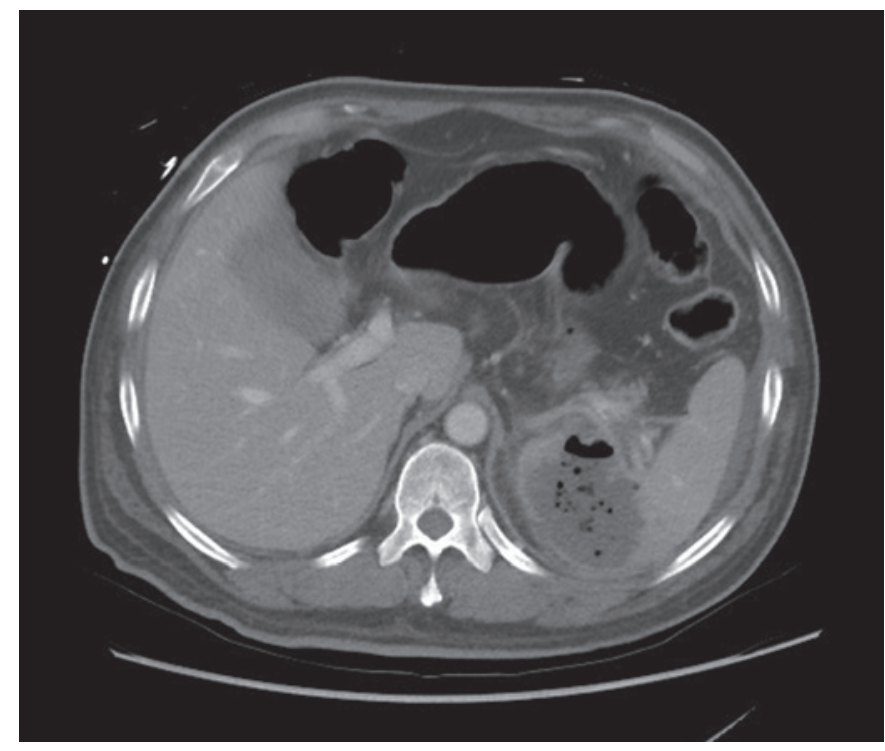

Fig. 1. Abdominal CT scan axial view showing collection with multiple air pockets.

he was hypotensive $(93 / 65 \mathrm{~mm} \mathrm{Hg})$ and tachycardic (116/min) and was afebrile. On abdominal examination, he was noted to have generalized abdominal tenderness with distention. His WBC was $5.2 \times 10^{3} / \mu \mathrm{L}$ and C-reactive protein was raised to $300.4 \mathrm{mg} / \mathrm{L}$. His liver and renal functions were also deranged. In view of his sepsis, a nasopharyngeal swab specimen was obtained to rule out the novel coronavirus. COVID-19 was detected, an initial chest X-ray, however, showed no consolidation.

CT abdominal angiogram was performed which showed findings of a splenic abscess with multiple gas shadows suggestive of pyogenic abscess with impending/contained perforation, colonic wall thickening with intramural gas shadows and mucosal hyperenhancement and small intraperitoneal gas indicating pneumoperitoneum. The abdominal vessels, however, were reported as normal with no filling defects (Fig. 1, 2).

The patient underwent an urgent exploratory laparotomy, which revealed ruptured splenic abscess; and splenectomy was done. Postoperatively, he was kept in the surgical intensive care unit where he remained intubated and received inotropic support (noradrenaline) along with intravenous antibiotics.

The intra-abdominal fluid sample taken during surgery came out to be positive for Streptococcus pseudopneumoniae. Blood and urine culture showed no growth. The histomorphological features of the resected spleen were reported to be consistent with the clinical diagnosis of splenic abscess (abundant fibrinosuppurative necrosis and dense acute [neutrophilic] inflammatory cell infiltrate with admixed karyorrhectic [nuclear] debris).

The patient continued to show a picture of severe sepsis and multiorgan failure. Repeat nCOV swabs remained positive. Repeated CT chest and abdomen with contrast showed acute segmental and subsegmental pulmonary emboli and small residual abdominal collection.

He remained critically ill in the intensive care unit, developed asystole on postoperative day 16 , and died.

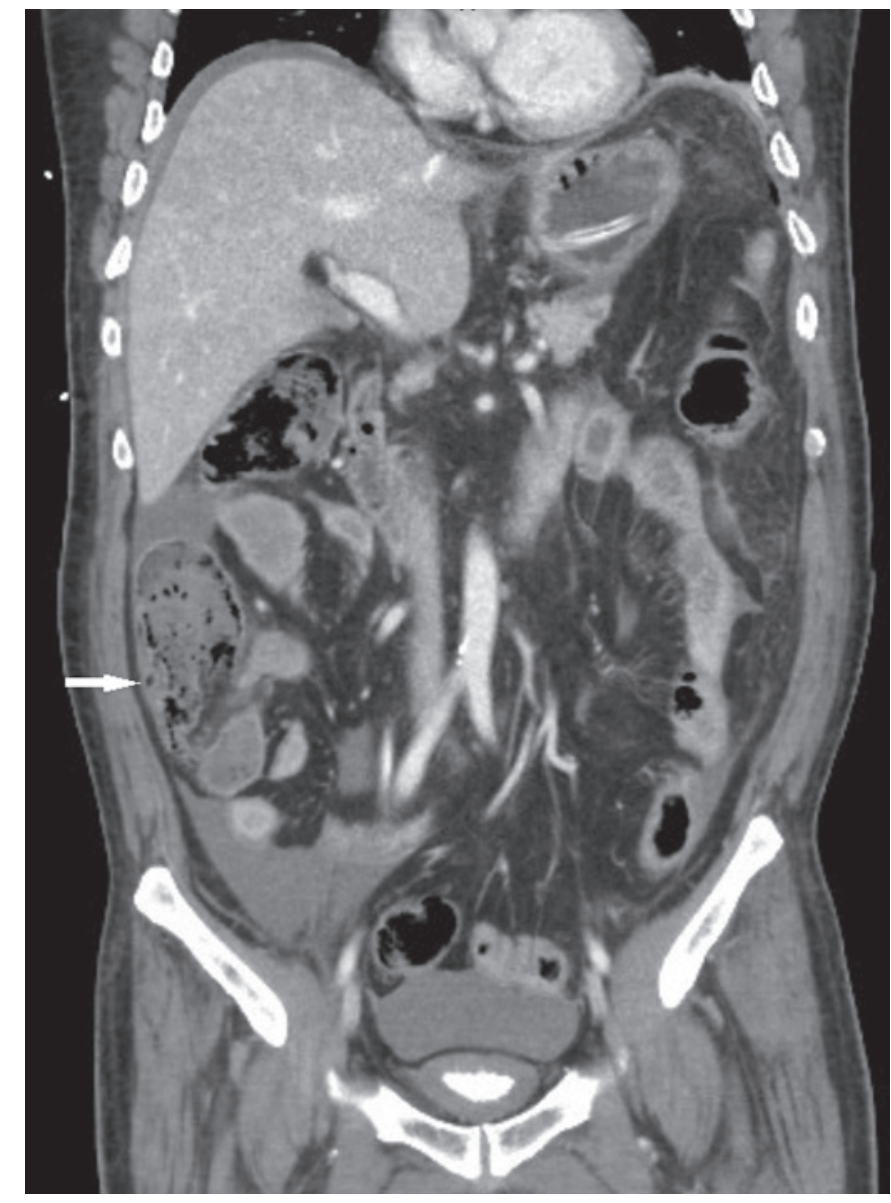

Fig. 2. Abdominal CT coronal view showing intramural gas shadows in the ascending colon, with irregular wall thickening and edema (arrow).

\section{Discussion}

Splenic abscess is a rare but life-threatening infection. It occurs often in patients with underlying disease. Immunosuppressed patients are one of the high-risk groups to develop splenic abscess, and mortality could be related to the underlying immunodeficiency [1].

The cause of splenic abscess is mainly hematogenous, with infective endocarditis being the most common source [2]. It may develop as a spread from distant or nearby contiguous sites of infection such as appendicitis, diverticulitis, perforated bowel or pelvic infection, splenic trauma, or haemoglobinopathies. Gram-negative bacillus is the predominant pathogen isolated, and the most common organisms grown were Klebsiella pneumoniae, Escherichia coli, and Staphylococcus aureus [3-5].

The choice of treatment ranges from antibiotics alone, percutaneous drainage, or splenectomy. It depends on 
Fig. 3. White pulp with localized lymphoid hyperplasia. Some lymphoid follicles are seen without formation of germinal centers, and others show expanded mantle zone and indistinct marginal zone. In other areas, the white pulp shows disorganization and depletion of lymphoid follicles.

Fig. 4. Splenic capsular area showing abscess with inflammatory infiltration by abundant neutrophils, aggregates of foamy macrophages, lymphocytes, plasma cells, and eosinophils.
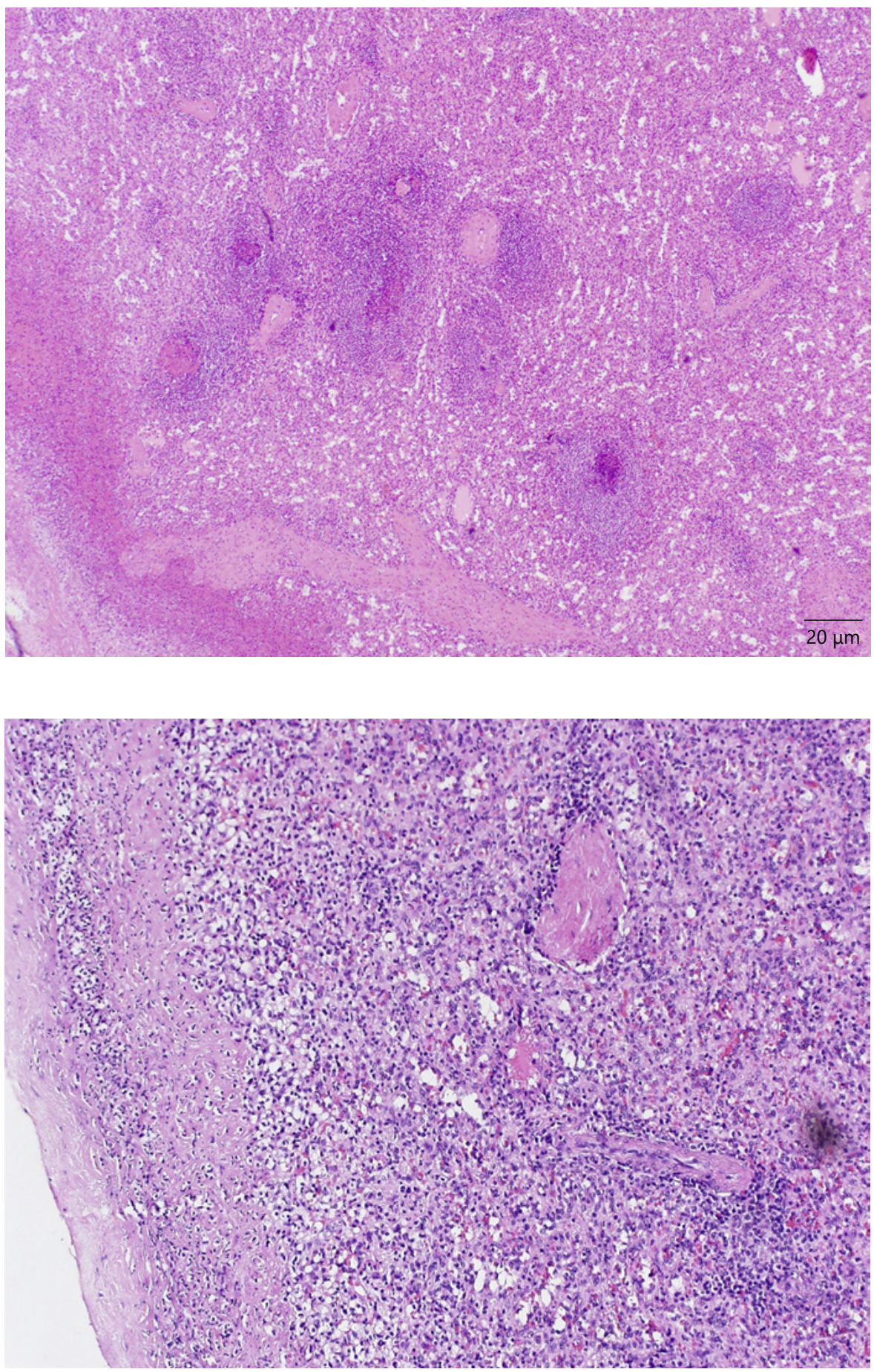

the general condition of the patient, the size of the abscess, whether it is single or multiple, and the presence of other extrasplenic abscess. Percutaneous drainage is a safe, effective, and noninvasive therapy [6].

In addition to the respiratory system, the gastrointestinal tract and other organs may also be targets of infec- tion by COVID-19. Previous studies showed that SARS coronavirus (SARS-CoV) invades various organs of the body $[7,8]$. A metallopeptidase named angiotensin-converting enzyme 2 (ACE2) has been identified as the functional receptor for SARS-CoV. The spike (S) glycoprotein of 2019-nCoV binds ACE2 with higher affinity than 
SARS-CoV S [9]. ACE2 was present in arterial and venous endothelial cells and arterial smooth muscle cells in all organs [10]. It is highly expressed in the lungs, in addition to absorptive enterocytes from the ileum and colon [11]. One of the initial complaints of our patient was diarrhea. Liang et al. [12] found that the incidence of diarrhea was underestimated in COVID-19 cohorts in comparison to SARS-CoV even though it is known that ACE2 controls acute intestinal inflammation, and such interaction may lead to diarrhea.

Moreover, SARS-CoV infection causes massive necrosis of the spleen and lymph nodes. The development of a splenic abscess in a COVID-19-positive patient could be due to direct attack of the spleen by the virus. A study conducted by Zhan et al. [13] demonstrated that the SARS virus infects the spleen and damages it as well as other lymphoid tissue. Hemorrhagic necrosis was present in the spleens of all confirmed SARS studied. Other pathological findings described included extensive necrosis of the spleen and atrophy of the white pulp with severe lymphocyte depletion [14]. The pathological findings in our case showed lymphoid hyperplasia, disorganization, and depletion of lymphoid follicles in the white pulp. It shows also inflammatory infiltration by abundant neutrophils (Fig. 3, 4).

It was hypothesized that splenic immune system collapse may play a role in the clinical outcome of these patients. If true, our patient's splenic abscess and his urgent need for splenectomy could have been one of the risk factors of his unfortunate clinical outcome.

\section{Conclusion}

COVID-19 mainly affects the respiratory system but extrapulmonary affection has been reported. Direct invasion and damage to the organs by the virus could be the reason behind the development of the extrapulmonary manifestations. Healthcare workers need to be vigilant and maintain a high index of suspicion for atypical presentations and gastrointestinal symptoms.

\section{Statement of Ethics}

Informed consent and approval were obtained by the ethical committee.

\section{Conflict of Interest Statement}

The authors have no conflicts of interest to disclose.

\section{Funding Sources}

No sources of support were received for this study.

\section{Author Contributions}

L.S.O.: Writing, review, and editing. M.O.A.: Data collection. M.M.: Data collection. OMA: Literature review. HAB: Literature review. TRK: Slides preparation.

\section{References}

1 Mei-Chun Lee, Chun-Ming Lee. Splenic Abscess: An Uncommon Entity with Potentially Life-Threatening Evolution. Canadian Journal of Infectious Diseases and Medical Microbiology Volume 2018, Article ID 8610657, https://doi.org/https://doi.org/10.1155/ 2018/8610657.

2 Chun CH, Raff MJ, Contreras L, Varghese R, Waterman N, Daffner R, et al. Splenic abscess. Medicine (Baltimore). 1980 Jan;59(1):50-65.

3 Brook I, Frazier EH. Microbiology of liver and spleen abscesses. J Med Microbiol. 1998 Dec; 47(12):1075-80.

4 Sreekar H, Saraf V, Pangi AC, Sreeharsha H, Reddy R, Kamat G. A retrospective study of 75 cases of splenic abscess. Indian J Surg. 2011 Dec;73(6):398-402.

5 Chang KC, Chuah SK, Changchien CS, Tsai TL, Lu SN, Chiu YC, et al. Clinical characteristics and prognostic factors of splenic abscess: a review of 67 cases in a single medical center of Taiwan. World J Gastroenterol. 2006 Jan;12(3):460-4.
6 Thanos L, Dailiana T, Papaioannou G, Nikita A, Koutrouvelis H, Kelekis DA. Percutaneous CT-Guided Drainage of Splenic Abscess. AJR Am J Roentgenol. 2002;179(3):629-32.

7 Zhang QL1. Ding YQ, Hou JL. Detection of severe acute respiratory syndrome (SARS)associated coronavirus RNA in autopsy tissues with in situ hybridization. J First Mil Med Univ. 2003 Nov;23(11):1125-7.

8 Ding Y, He L, Zhang Q, Huang Z, Che X, Hou $\mathrm{J}$, et al. Organ distribution of severe acute respiratory syndrome (SARS) associated coronavirus (SARS-CoV) in SARS patients: implications for pathogenesis and virus transmission pathways. J Pathol. 2004 Jun;203(2): 622-30.

9 Wrapp D, Wang N, Corbett KS, Goldsmith JA, Hsieh CL, Abiona O, et al. Cryo-EM structure of the 2019-nCoV spike in the prefusion conformation. Science. 2020 Mar;367(6483): $1260-3$.
10 Hamming I, Timens W, Bulthuis ML, Lely AT, Navis G, van Goor H. Tissue distribution of ACE2 protein, the functional receptor for SARS coronavirus. A first step in understanding SARS pathogenesis. J Pathol. 2004 Jun; 203(2):631-7.

11 Zhang H, Kang Z, Gong H. A-The digestive system is a potential route of 2019-nCov infection: a bioinformatics analysis based on single-cell transcriptomes. doi: https://doi.org/ https://doi.org/10.1101/2020.01.30.927806.

12 Liang W, Feng Z, Rao S, Xiao C. Diarrhoea may be underestimated: a missing link in 2019 novel coronavirus. Gut. 2020 Feb 26. pii: gutjnl-2020-320832. doi: https://doi.org/10. 1136/gutjnl-2020-320832.

13 Zhan J, Deng R, Tang J, Zhang B, Tang Y, Wang JK, et al. The spleen as a target in severe acute respiratory syndrome. FASEB J. 2006 Nov;20(13):2321-8.

$14 \mathrm{Gu}$ J, Korteweg C. Pathology and pathogenesis of severe acute respiratory syndrome. Am J Pathol. 2007 Apr;170(4):1136-47. 